\title{
Case Report: Vocal cord collapse during phrenic nerve-paced \\ respiration in congenital central hypoventilation syndrome
}

\section{[version 1; peer review: 2 approved]}

\author{
Mark C Domanski ${ }^{1}$, Diego A Preciado² \\ ${ }^{1}$ Department of Surgery, University of Mississippi, Jackson, MS, 39216, USA \\ 2Department of Otolaryngology, Children's National Medical Center, Washington, D.C., 20010-2970, USA
}

V1 First published: 01 Nov 2012, 1:42

https://doi.org/10.12688/f1000research.1-42.v1

Latest published: 01 Nov 2012, 1:42

https://doi.org/10.12688/f1000research.1-42.v1

\section{Abstract}

Objective: Phrenic nerve pacing can be used to treat congenital central hypoventilation syndrome (CCHS). We report how the lack of normal vocal cord tone during phrenic paced respiration can result in passive vocal cord collapse and produce obstructive symptoms. Methods: We describe a case of passive vocal cord collapse during phrenic nerve paced respiration in a patient with CCHS. As far as we know, this is the first report of this etiology of airway obstruction. The patient, a 7-year-old with CCHS and normal waking vocal cord movement, continued to require nightly continuous positive airway pressure (CPAP) despite successful utilization of phrenic nerve pacers. On direct laryngoscopy, the patient's larynx was observed while the diaphragmatic pacers were sequentially engaged.

Results: No abnormal vocal cord stimulation was witnessed during engaging of either phrenic nerve stimulator. However, the lack of normal inspiratory vocal cord abduction during phrenic nerve-paced respiration resulted in vocal cord collapse and partial obstruction due to passive adduction of the vocal cords through the Bernoulli effect. Bilateral phrenic nerve stimulation resulted in more vocal cord collapse than unilateral stimulation.

Conclusions: The lack of vocal cord abduction on inspiration presents a limit to phrenic nerve pacers.

\section{Keywords}

Ondine's curse, congenital central hypoventilation syndrome, phrenic nerve pacing , obstructive sleep apnea, vocal cord

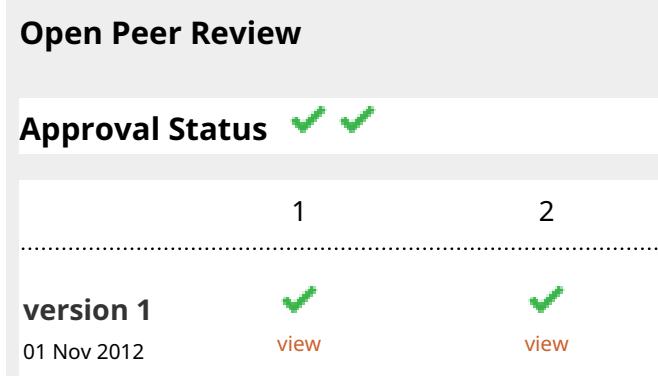

1. Nina Shapiro, University of California, Los Angeles School of Medicine, Los Angeles, CA, USA

\section{Anastasios G Hantzakos, University of} Athens, Hippocrateion General Hospital, Athens, Greece

Any reports and responses or comments on the article can be found at the end of the article. 
Corresponding author: Mark C Domanski (mcdomanski@gmail.com)

Competing interests: No competing interests were disclosed.

Grant information: The author(s) declared that no grants were involved in supporting this work.

Copyright: $\odot 2012$ Domanski MC and Preciado DA. This is an open access article distributed under the terms of the Creative Commons Attribution License, which permits unrestricted use, distribution, and reproduction in any medium, provided the original work is properly cited. Data associated with the article are available under the terms of the Creative Commons Zero "No rights reserved" data waiver (CC0 1.0 Public domain dedication).

How to cite this article: Domanski MC and Preciado DA. Case Report: Vocal cord collapse during phrenic nerve-paced respiration in congenital central hypoventilation syndrome [version 1; peer review: 2 approved] F1000Research 2012, 1:42

https://doi.org/10.12688/f1000research.1-42.v1

First published: 01 Nov 2012, 1:42 https://doi.org/10.12688/f1000research.1-42.v1 


\section{Introduction}

Congenital central hypoventilation syndrome (CCHS) is a rare disorder typified by the lack of ventilatory responsiveness to hypoxemia and hypercarbia. The patient with CCHS will typically have adequate conscious control of breathing when awake. However, when asleep, the anatomic nervous system fails to maintain respiration. Patients with CCHS may have other disorders of the autonomic nervous system such as Hirschsprung's disease, lack of heart rate variability, poor temperature regulation, and diminished pupillary light response. Tumors of neural crest origin such as ganglioneuromas, neuroblastomas and ganglioneuroblastomas are also associated with $\mathrm{CCHS}^{1}$.

CCHS is a rare clinical entity. CCHS was first described in 1970s by Mellins et al. ${ }^{2}$. As of 1999, it was estimated that there were only 200-300 patients with CCHS worldwide ${ }^{3}$.

CCHS is caused by a heterogeneous mutation in PHOX2B. PHOX2B is highly conserved transcription factor found on chromosome 4p12. PHOX2B is expressed in both the central and peripheral autonomic nervous system during human development. A mouse model of CCHS showed that Phox2B -/- mice fail to develop the normal neuronal connections of several structures including the solitary tract $t^{4,5}$.

Children with CCHS typically present soon after birth with duskiness or cyanosis upon falling asleep. During sleep, falling oxyhemoglobin saturation and rising carbon dioxide levels fail to increase respiration or awaken the infant. The differential diagnosis includes discrete congenital myopathy, myasthenia gravis, altered airway anatomy, diaphragm dysfunction, congenital cardiac disease, a structural hindbrain or brainstem abnormality, Mobius syndrome, and inborn errors of metabolism ${ }^{1}$.

Evaluation of suspected CCHS may include a muscle biopsy, chest $\mathrm{x}$-ray, fluoroscopy of the diaphragm, bronchoscopy, electrocardiogram, Holter recording, echocardiogram, magnetic resonance imaging of the brain and brainstem, serum and urinary carnitine levels. Ophthalmological evaluation should assess for pupillary reactivity and optic disk anatomy. A rectal biopsy should be considered because of the association with Hirschsprung's disease ${ }^{1}$.

Treatment of the respiratory compromise in CCHS consists of a tracheostomy and adequate ventilatory support. Because of the persistent lack of response to hypoxemia and hypercarbia, frequent monitoring of pulse oximetry and end tidal $\mathrm{CO}_{2}$ may be prudent ${ }^{1}$. Once the child reaches appropriate age, insertion of diaphragmatic pacers may be considered ${ }^{6}$. Diaphragmatic pacers work by stimulating the phrenic nerve in the chest, resulting in diaphragm contraction and respiration. The energy for stimulation is provided by an external portable power source. Successful use of diaphragmatic stimulation may in some cases allow for tracheal decannulation ${ }^{1}$.

Normal respiration is more than just appropriate diaphragmatic response to hypoxemia and hypercarbia. During inspiration, the vocal cords abduct. Classically, this "V-shaped" aperture is called the glottic "chink" . If the vocal cords were not actively abducted during inspiration, they would be drawn together via the Bernoulli effect ${ }^{8}$.

\section{Case Description}

A seven year-old female presented with a history of CCHS and a current complaint of obstructive sleep apnea requiring continuous positive airway pressure (CPAP).

In the newborn period, the patient had been managed with a tracheostomy and traditional ventilatory support. An extensive workup failed to demonstrate any other major developmental abnormalities. In the preschool years, she received bilateral placement of intrathoracic diaphragmatic pacers that eventually allowed decannulation.

During the day the patient ambulated with an external power source that was programmed to stimulate the pacing wires if she did not take any breaths in a predefined time period. This was in case the patient accidentally fell asleep. At night the device was set to provide her with continuous respirations. However, at night, the patient also required continuous positive airway pressure because of an obstructive component of her sleep apnea.

Flexible nasal laryngoscopy showed no adenotonsillar hypertrophy. Pharyngeal and tongue anatomy was normal. Vocal cords movement was normal, including abduction during inspiration (Figure 1).

The patient was scheduled for evaluation in the operating room under general anesthesia. The patient received a preoperative dose of oral midazolam. In the operating room the phrenic pacers were turned off and general anesthesia was induced using inhalational agents. Muscle relaxants were not used. The patient was masked without difficulty. Direct laryngoscopy was performed without an endotracheal tube in place. No laryngeal structural pathology was found. Bronchoscopy using a rigid $4 \mathrm{~mm}$ Hopkins rod showed a well-healed tracheostomy site without any granulation or tracheomalacia (Figure 2).

Because of the patient's diaphragmatic pacers, it was possible to observe how the patient "normally" breathed while asleep. While performing direct laryngoscopy, we proceeded to turn on the right and left phrenic nerve pacers individually and then together. Unilateral stimulation of the diaphragm resulted in respiration. No active stimulation such as myoclonus, abduction or abduction of the vocal cords was noted. However, during inspiration the true vocal cords were pulled medially. This was most evident at the start of inspiration. Expiration resulted in flutter of the vocal cords most

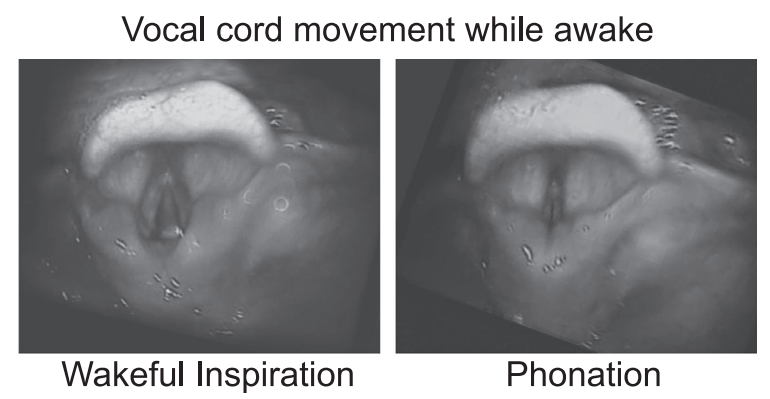

Figure 1. Flexible laryngoscopy showed normal function while awake. 


\section{Bronchoscopy}

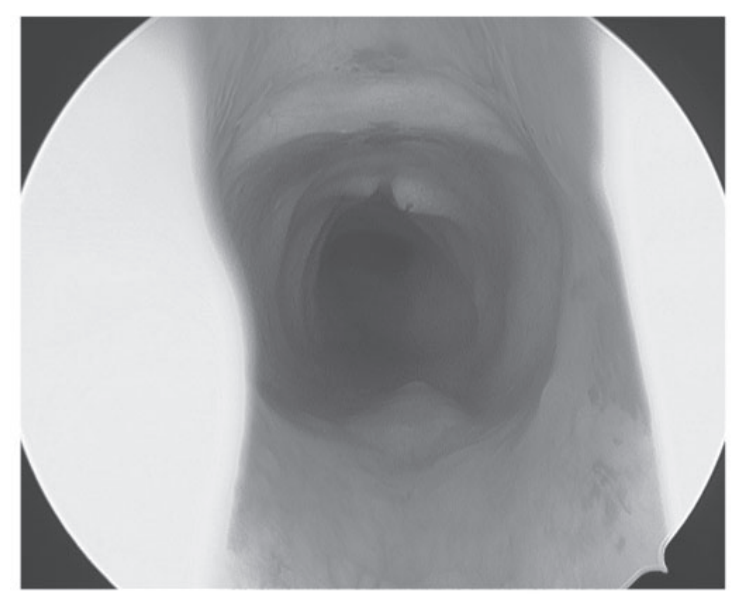

\section{Site of previous trachostomy}

Figure 2. Bronchosopy failed to identify any site of lower airway obstruction.

prominent at the anterior commissure. Bilateral phrenic nerve stimulation produced greater respiratory efforts. This was accompanied by greater medial pull of the true vocal cords during inspiration along with audible stridor. Flutter of the vocal cords on expiration was greater as well (Figure 3).
Once the examination was complete, the patient was awoken in the operating room. The patient's phrenic nerve pacers were turned on while positive pressure was provided via masking-allowing the child to breath while still under anesthesia. As the child awoke, she gradually took voluntary control of her respiration at which time the phrenic pacers automatically ceased.

\section{Conclusion}

CCHS is a rare, multifaceted disorder involving severe central sleep apnea. Treatment is supportive, including aggressive respiratory support such a tracheostomy and sleep-time ventilatory support. Phrenic nerve pacing can obviate the need for external ventilator support, allowing the patient to be considered for decannulation. However, decannulation means that during sleep, air will pass by the vocal cords. As demonstrated in this case report, the vocal cords do not function normally in phrenic nerve-paced respiration. Because there is no central respiratory drive, there is no stimulation for the vocal cords to abduct on inspiration. Instead, during phrenic nerve pacer respiration, the vocal cords are drawn together via the Bernoulli effect and obstructive sleep apnea can result.

As many children with CCHS develop sequelae compatible of intermittent hypoxemia, passive True Vocal Chord (TVC) collapse is important to consider when evaluating their sleep apnea. The lack of normal vocal cord abduction on inspiration presents a limitation to diaphragmatic paced respiration. Our patient required CPAP while asleep for this reason.

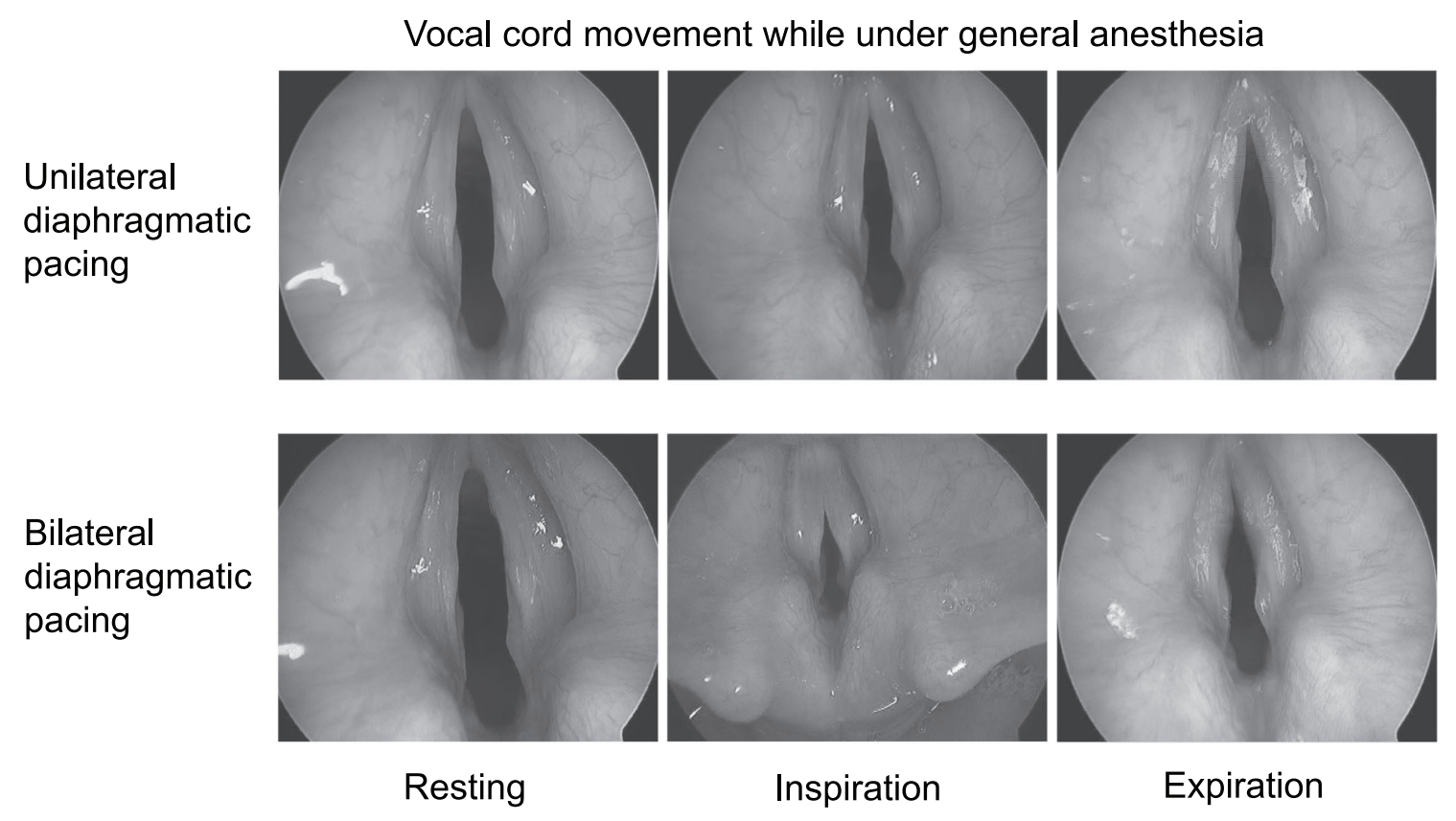

Figure 3. Direct laryngoscopy while asleep and breathing via diaphragmatic pacing. Vocal cord collapse was greater during bilateral than unilateral diaphragmatic pacing. 
Author contributions

MCD provided the description of the case and wrote up the manuscript. DP provided the editorial insight and the overall conclusion.

Competing interests

No competing interests were disclosed.
Grant information

The author(s) declared that no grants were involved in supporting this work.

\section{Acknowledgment}

The authors would like to thank Dr. Joseph Goodman for his assistance with this work.
1. Idiopathic congenital central hypoventilation syndrome: diagnosis and management. American Thoracic Society. Am J Respir Crit Care Med. 1999; 160(1): 368-73.

PubMed Abstract | Publisher Full Text

2. Mellins $\mathrm{RB}$, Balfour $\mathrm{HH}$, Turino $\mathrm{GM}$, et al: Failure of automatic control of ventilation (Ondine's curse). Report of an infant born with this syndrome and review of the literature. Medicine (Baltimore). 1970; 49(6): 487-504. PubMed Abstract

3. Silvestri JM, Chen ML, Weese-Mayer DE, et al: Idiopathic congenital central hypoventilation syndrome: the next generation. Am J Med Genet. 2002; 112(1): $46-50$.

PubMed Abstract | Publisher Full Text

4. Amiel J, Laudier B, Attie-Bitach T, et al.: Polyalanine expansion and frameshift mutations of the paired-like homeobox gene PHOX2B in congenital central hypoventilation syndrome. Nat Genet. 2003; 33(4): 459-461.

PubMed Abstract | Publisher Full Text
5. Dubreuil V, Ramanantsoa N, Trochet D, et al:: A human mutation in Phox2b causes lack of $\mathrm{CO} 2$ chemosensitivity, fatal central apnea, and specific loss of parafacial neurons. Proc Natl Acad Sci U S A. 2008; 105(3): 1067-1072. parafacial neurons. Proc Natl Acad Sci U S A. 2008; 105

6. Chen ML, Tablizo MA, Kun S, et al:: Diaphragm pacers as a treatment for congenital central hypoventilation syndrome. Expert Rev Med Devices. 2005 2(5): 577-585.

2(5): $577-585$.
PubMed Abstract | Publisher Full Text

7. Hicks M, Brugman SM, Katial R: Vocal cord dysfunction/paradoxical vocal fold motion. Prim Care. 2008; 35(1): 81-103, vii.

PubMed Abstract | Publisher Full Text

8. Gates RK: The owner's manual to the singing voice. Columbus, Ohio: The Ohio State University 2002.

Reference Source 


\section{Open Peer Review}

\section{Current Peer Review Status:}

\section{Version 1}

Reviewer Report 11 November 2012

https://doi.org/10.5256/f1000research.211.r363

(C) 2012 Hantzakos A. This is an open access peer review report distributed under the terms of the Creative Commons Attribution License, which permits unrestricted use, distribution, and reproduction in any medium, provided the original work is properly cited.

\section{Anastasios G Hantzakos}

1st Department of Orolaryngology, Head and Neck Surgery, University of Athens, Hippocrateion General Hospital, Athens, Greece

Interesting paper! It would be further appreciated if the authors could add a section labeled "Discussion" where the details on the principles of PNP respiration and proposed solutions to prevent obstruction could be noted.

Competing Interests: No competing interests were disclosed.

I confirm that I have read this submission and believe that I have an appropriate level of expertise to confirm that it is of an acceptable scientific standard.

Reviewer Report 02 November 2012

\section{https://doi.org/10.5256/f1000research.211.r362}

(C) 2012 Shapiro N. This is an open access peer review report distributed under the terms of the Creative Commons Attribution License, which permits unrestricted use, distribution, and reproduction in any medium, provided the original work is properly cited.

\section{Nina Shapiro}

Division of Head and Neck Surgery, University of California, Los Angeles School of Medicine, LoS Angeles, CA, USA

This is an excellent review of a rare disorder, Congenital Central Hypoventilation Syndrome. The authors present a thorough presentation of the nature of this disorder, followed by an illustrative case of a patient who developed paradoxical vocal cord mobility during phrenic nerve stimulation.

Utilization of phrenic nerve-paced respiration is carried out in effort to obviate the need for 
tracheotomy tube placement in these patients. However, the authors noted that this technique can lead to absence of vocal cord abduction on inspiration, which in turn leads to vocal fold closure and airway obstruction, secondary to the Bernouilli effect. Intraoperative photos are provided, as well as the outcome for this, and potentially future patients seen with this disorder.

Competing Interests: No competing interests were disclosed.

I confirm that I have read this submission and believe that I have an appropriate level of expertise to confirm that it is of an acceptable scientific standard.

The benefits of publishing with F1000Research:

- Your article is published within days, with no editorial bias

- You can publish traditional articles, null/negative results, case reports, data notes and more

- The peer review process is transparent and collaborative

- Your article is indexed in PubMed after passing peer review

- Dedicated customer support at every stage

For pre-submission enquiries, contact research@f1000.com 